\title{
Cholinergic-opioidergic interaction in the central amygdala induces antinociception in the guinea pig
}

C.R.A. Leite-Panissi ${ }^{1}$, M.R. Brentegani ${ }^{2}$ and L. Menescal-de-Oliveira ${ }^{2}$
${ }^{1}$ Departamento de Morfologia, Estomatologia e Fisiologia, Faculdade de Odontologia de Ribeirão Preto, Universidade de São Paulo, Ribeirão Preto, SP, Brasil

${ }^{2}$ Departamento de Fisiologia, Faculdade de Medicina de Ribeirão Preto, Universidade de São Paulo, Ribeirão Preto, SP, Brasil

\section{Correspondence}

L. Menescal-de-Oliveira

Departamento de Fisiologia

FMRP, USP

14049-900 Ribeirão Preto, SP

Brasil

Fax: +55-16-633-0017

E-mail: Imdolive@fmrp.usp.br

Research supported by CNPq, CAPES, FAEPA and FAPESP (No. 97/14286-9).

Received October 10, 2003 Accepted July 5, 2004

\begin{abstract}
Several studies have demonstrated the involvement of the central nucleus of the amygdala (CEA) in the modulation of defensive behavior and in antinociceptive regulation. In a previous study, we demonstrated the existence of a cholinergic-opioidergic interaction in the CEA, modulating the defensive response of tonic immobility in guinea pigs. In the present study, we investigated a similar interaction in the CEA, but now involved in the regulation of the nociceptive response. Microinjection of carbachol $(2.7 \mathrm{nmol})$ and morphine (2.2 nmol) into the CEA promoted antinociception up to $45 \mathrm{~min}$ after microinjection in guinea pigs as determined by a decrease in the vocalization index in the vocalization test. This test consists of the application of a peripheral noxious stimulus (electric shock into the subcutaneous region of the thigh) that provokes the emission of a vocalization response by the animal. Furthermore, the present results demonstrated that the antinociceptive effect of carbachol $(2.7 \mathrm{nmol} ; \mathrm{N}$ $=10)$ was blocked by previous administration of atropine $(0.7 \mathrm{nmol} ; \mathrm{N}$ $=7)$ or naloxone ( $1.3 \mathrm{nmol} ; \mathrm{N}=7)$ into the same site. In addition, the decrease in the vocalization index induced by the microinjection of morphine ( $2.2 \mathrm{nmol} ; \mathrm{N}=9$ ) into the CEA was prevented by pretreatment with naloxone $(1.3 \mathrm{nmol} ; \mathrm{N}=11)$. All sites of injection were confirmed by histology. These results indicate the involvement of the cholinergic and opioidergic systems of the CEA in the modulation of antinociception in guinea pigs. In addition, the present study suggests that cholinergic transmission may activate the release of endorphins/ enkephalins from interneurons of the CEA, resulting in antinociception.
\end{abstract}

\section{Introduction}

The central nucleus of the amygdala (CEA) is involved in diverse emotional and cognitive functions related to responses of fear and orientation $(1,2)$, defensive behavior $(3,4)$, and
Key words

- Antinociception

- Vocalization test

- Cholinergic-opioidergic

interaction

- Amygdala

- Naloxone

- Atropine cardiovascular regulation (5). In addition, various reports in the literature have indicated that the amygdala is one of the important sites of the modulation of antinociception (3,6-8). Indeed, the amygdala is considered to be a terminal site of the disynaptic nociceptive spino 
(trigemio)pontoamygdaloid pathway with relay in the parabrachial area (9). This pathway is probably involved in the affectiveemotional (fear, aggression), behavioral (vocalization, fight, freezing) and autonomic (cardiovascular and respiratory responses) reactions to noxious events (9).

Fox and Sorenson (7) have shown that lesion of the CEA promoted a reduction in antinociception induced by meeting a predator and also in antinociception promoted by classical conditioning evaluated by the tailflick test. These results suggest the involvement of the CEA in the regulation of antinociception induced by aversive events.

Some reports have demonstrated the existence of peptides and amino acids in the amygdala, that participate in neurotransmission and also of various neurotransmitters such as acetylcholine and enkephalin. Indeed, enzymes related to acetylcholine processing (acetylcholinesterase and choline acetyltransferase) are present in the lateral part of the CEA, indicating that acetylcholine synthesis occurs in the amygdala (10). In addition, some studies have demonstrated the existence of diverse neurons containing enkephalin in the amygdaloid complex (11). In this respect, it has been shown that the administration of morphine into the amygdala promotes an increase of the nociceptive threshold in different algesimetric tests (12, 13). Pavlovic et al. (14) observed that microinjection of morphine or B-endorphin into the amygdala produced a significant increase of latency in the tail-flick test as well as in the jump test in rats. Furthermore, the increase in tail-flick latency and jump threshold was prevented by pretreatment with opioid antagonists (naltrexone, $\beta$-funaltrexamine and naltrindole isothiocyanate) injected into the periaqueductal gray matter (PAG). Taken together, these results suggest that the existence of opioidergic synapses in the PAG is essential for the antinociceptive effect on opioidergic stimulation of the amygdala in rats.
It has been demonstrated that microinjection of the cholinergic agonist, carbachol, into the CEA, but not into the basolateral or lateral nuclei of the amygdala, produced an increase in tail-flick latency (3). In addition, Ahn et al. (8) showed that carbachol administered into the CEA promoted antinociception in rats after the application of a noxious electric stimulus to the dental pulp and this effect was blocked by pretreatment with atropine at the same site. Furthermore, in a previous study (15) we demonstrated that the cholinergic system of the CEA participates in the modulation of defensive behavior and also in antinociception through a functional and anatomical connection with the ventrolateral PAG, because pretreatment with lidocaine injected into the ventrolateral PAG blocked the decrease in the duration of the defensive behavior of tonic immobility and the reduction of the vocalization index after carbachol microinjection into the CEA.

The existence of a circuit in the CEA that modulates the defensive response of tonic immobility has been described (16). We showed that a cholinergic-opioidergic interaction in the CEA is involved in the modulation of this defensive behavior. Thus, cholinergic and opioidergic stimulation of the CEA exerts an inhibitory action on the duration of tonic immobility episodes in guinea pigs. Furthermore, the effect of the administration of carbachol and morphine into the CEA was blocked by pretreatment with naloxone microinjected into the same site.

The objective of the present study was to evaluate the possibility of the existence in the CEA of a similar circuit that may participate in the modulation of the nociceptive response. To this end, we investigated whether microinjection of carbachol, atropine, morphine, and naloxone into the CEA of different groups of guinea pigs produces alterations in the nociceptive response evaluated on the basis of vocalization produced by a peripheral noxious stimulus of low intensity (electric shock). 


\section{Material and Methods}

Adult male guinea pigs (Cavia porcellus) weighing 400-500 $\mathrm{g}$ were obtained from the animal care facility of the Faculty of Medicine of Ribeirão Preto (FMRP). The animals were kept in Plexiglas wall cages (56 x $37 \mathrm{x}$ $39 \mathrm{~cm}, 5$ animals per cage) in a room maintained at $24 \pm 1^{\circ} \mathrm{C}$, on a 12-h light cycle, with free access to water and food. Experiments were carried out according to the ethical recommendations of the Committee for Research and Ethical Issues of the International Association for the Study of Pain (17).

Antinociception was determined by the vocalization test. Guinea pigs are not commonly used in experiments destined to the study of the neural mechanisms of analgesia. Algesimetric tests currently used in rats and mice are not applicable to guinea pigs for anatomical reasons (tail-flick) or because they have not been standardized (writhing). In our laboratory, we have been using for some years tests that have proved to be appropriate for guinea pigs $(15,18,19)$. The vocalization test consists of the application of a peripheral noxious stimulus (electric shock) that provokes the emission of a vocalization response by the animal, which is interpreted as a manifestation of pain.

For peripheral noxious stimulation, a pair of non-insulated electrodes was implanted into the subcutaneous region of the thigh. The animal was then placed in an acrylic box lined with nylon foam where some movement was possible. After $20 \mathrm{~min}$ of animal habituation to the experimental situation, the electrode was connected to an electronic stimulator that released pulses (square waves, $100-\mathrm{Hz}$ frequency, 0.5 -ms duration) of varying intensity $(0.5$ to $4.0 \mathrm{~V})$ sufficient to induce vocalization. Once the threshold value was established, voltage was maintained at a constant level throughout the experiment. The electric shock (3-s duration) induced brief motor and vocalization responses that did not persist in the intervals between stimuli.
The peripheral noxious stimulus was then applied 5, 15, 30, 45, 60, and $75 \mathrm{~min}$ after the different treatments. Vocalization was recorded with an Aiwa DM-64 microphone connected to the pre-amplifier of a polygraph. In the polygraphic recording of vocalization, the peak amplitude is proportional to the intensity of animal vocalization. The mean peak of each response is a reliable index of the magnitude of vocalization. The peak amplitude of the graphic vocalization recordings was measured in millimeters and the mean of each response was used for quantitative evaluation. As a control, a baseline test was performed to determine the smallest noxious stimulus necessary to produce a vocalization response by the animal. Three consecutive noxious stimuli were applied and the mean vocalization amplitude was calculated for control periods (without saline or drug administration).

For guide cannula implantation, the animals were anesthetized with sodium pentobarbital (Nembutal, $40 \mathrm{mg} / \mathrm{kg}$, ip) and placed in a stereotaxic apparatus (David-Kopf Instruments, Tujunga, CA, USA) with the mouthpiece $21.4 \mathrm{~mm}$ below the interauricular line, and one guide cannula prepared from a hypodermic needle (measuring $14 \mathrm{~mm}$ in length and $0.6 \mathrm{~mm}$ OD) was implanted into the left hemisphere toward the CEA. According to the atlas of Rössner for guinea pigs (20), the stereotaxic coordinates for placement of the guide cannula implanted toward the CEA were $3.4 \mathrm{~mm}$ caudal to the bregma, $6.1 \mathrm{~mm}$ lateral to the midline, and $7.5 \mathrm{~mm}$ below the cortical surface. The guide cannula was lowered to a depth of $1 \mathrm{~mm}$ above the target regions and fixed to the skull with self-polymerizing resin and an additional anchoring screw.

After recovery from surgery for 5-6 days, the animals were divided into six experimental groups and immediately submitted to the vocalization test after microinjection of the following drugs into the CEA. Group 1 animals $(\mathrm{N}=9)$ received $0.9 \%$ saline, group 
2 animals $(\mathrm{N}=10)$ were microinjected with carbachol (2.7 nmol), and group 3 animals $(\mathrm{N}=7)$ received atropine $(0.7 \mathrm{nmol})$, followed $10 \mathrm{~min}$ later by carbachol $(2.7 \mathrm{nmol})$ into the CEA. Group 4 animals $(\mathrm{N}=7)$ were microinjected with naloxone (1.3 nmol), followed $10 \mathrm{~min}$ later by microinjection of carbachol (2.7 nmol) into the CEA. Group 5 animals $(\mathrm{N}=9)$ received morphine sulfate $(2.2 \mathrm{nmol})$, and group 6 animals $(\mathrm{N}=11)$ were microinjected with naloxone $(1.3 \mathrm{nmol})$, followed $10 \mathrm{~min}$ later by morphine sulfate ( $2.2 \mathrm{nmol}$ ) into the CEA. Finally, to evaluate the separate effect of atropine and naloxone, two experimental groups were microinjected with atropine $(\mathrm{N}=5)$ or naloxone $(\mathrm{N}=5)$, followed $10 \mathrm{~min}$ later by saline into the CEA.

The microinjections were performed with a Hamilton microsyringe $(10 \mu \mathrm{l})$ connected to a $\mathrm{PE}-10$ polyethylene catheter, which in turn was coupled to a Mizzy needle segment (0.3 mm OD; $1 \mathrm{~mm}$ longer than the guide cannula). In all experimental groups, a volume of $0.2 \mu \mathrm{l}$ was microinjected over a period of $1 \mathrm{~min}$, and the Mizzy needle was left in place for an additional $40 \mathrm{~s}$ to prevent reflux.

Carbachol, atropine, naloxone, and morphine sulfate were obtained from Sigma, St. Louis, MO, USA. The drugs were dissolved in saline $(0.9 \%, \mathrm{w} / \mathrm{v}, \mathrm{NaCl})$. The doses employed were based on previous studies $(4,16)$.

After the end of the experiments, the animals were anesthetized with $50 \mathrm{mg} / \mathrm{kg}$ thionembutal and perfused intracardially with saline followed by $10 \%$ formalin. The brains were removed and fixed in $10 \%$ formalin. The material was then submitted to routine histological processing and sections were observed under a microscope to determine the locations of the stimulated sites according to the Rössner atlas (20). Only animals whose microinjection reached the target structure were used for data analysis.

The results of the amplitude of vocaliza- tion $(\mathrm{mm})$ were transformed into a vocalization index (VI) using the following formula: $\mathrm{VI}=$ mean vocalization - control value/control value. Data are reported as mean VI \pm SEM and were analyzed by repeated measures multivariate analysis of variance (MANOVA), with time (repeated factor) and treatment (independent factor) as variables, followed by one-way ANOVA and by the Duncan test. The level of significance was set at $\mathrm{P}<0.05$.

\section{Results}

Microinjection of carbachol and morphine sulfate into the CEA promoted antinociception in guinea pigs, as determined by the decrease of VI in the vocalization test (Figures 1A,B and 2). Furthermore, the present results demonstrated that the antinociceptive effect of carbachol (Figure 2B) was blocked by the previous administration of atropine (a muscarinic receptor antagonist) or naloxone (an opioidergic antagonist) into the same site (Figures 1A and 2C,D). In addition, the decrease in VI induced by microinjection of morphine sulfate (Figure 2E) into the CEA was prevented by pretreatment with naloxone (Figures 1B and 2F). Saline administration into the CEA did not alter the VI after administration of a noxious peripheral stimulus to the animal (Figures 1A,B and $2 \mathrm{~A}$ ), and this group was used as control in all other experiments. Furthermore, treatment with atropine or naloxone alone followed by saline did not promote significant alterations in the VI at any of the experimental time points.

Individual MANOVA applied to the different experimental groups revealed that carbachol and morphine sulfate administration into the CEA promoted a significant difference in the VI along the experiment $\left(\mathrm{F}_{6,54}=\right.$ 6.12, $\mathrm{P}<0.01$ for carbachol and $\mathrm{F}_{6,48}=5.48$, $\mathrm{P}<0.01$ for morphine sulfate treatment) when compared to the respective control (baseline before drug administration), at 5 
min after microinjection $(\mathrm{P}<0.05$, Duncan test), and this effect was observed up to 45 min after microinjection (Figure 1A,B). For the groups receiving saline, atropine + carbachol, naloxone + carbachol, and naloxone + morphine sulfate, statistical analysis did not show differences in VI with time after the microinjections $\left(\mathrm{F}_{6,48}=0.92, \mathrm{P}>0.05\right.$; $\mathrm{F}_{6,36}=0.52, \mathrm{P}>0.05 ; \mathrm{F}_{6,54}=0.80, \mathrm{P}>0.05$, and $\mathrm{F}_{6,60}=1.44, \mathrm{P}>0.05$, respectively, MANOVA).

For analysis of the experimental groups as a whole regarding VI variation after the different treatments, two-way ANOVA was performed, which showed a significant difference among treatments with time $\left(\mathrm{F}_{36,336}\right.$ $=1.75, \mathrm{P}<0.05$, MANOVA; Figure 1A,B). We then applied one-way ANOVA followed by the Duncan test to each experimental time interval. For the 5-min interval, there was a significant difference $\left(\mathrm{F}_{6,56}=3.7, \mathrm{P}<0.05\right.$, ANOVA) between the carbachol and morphine sulfate treatments when compared to the other groups $(\mathrm{P}<0.05$, Duncan test $)$; however, these groups did not differ from one another. Furthermore, saline, atropine + carbachol, naloxone + carbachol, and naloxone + morphine sulfate treatments did not differ from one another. This difference was also observed at the 15-, 30- and 45-min time intervals $\left(\mathrm{F}_{6,56}=5.6, \mathrm{P}<0.05 ; \mathrm{F}_{6,56}=4.8\right.$, $\mathrm{P}<0.05$, and $\mathrm{F}_{6.56}=4.7, \mathrm{P}<0.05$, ANOVA, respectively). The post hoc Duncan test showed a difference $(\mathrm{P}<0.05)$ between the carbachol and morphine sulfate treatments and all other treatments at the same time intervals as mentioned above (Figure 1A,B); however, there was no difference among the saline, atropine + carbachol, naloxone + carbachol, and naloxone + morphine sulfate groups. No difference between the experimental groups was observed at 60 or 75 $\min \left(\mathrm{F}_{6,56}=1.5, \mathrm{P}>0.05 ; \mathrm{F}_{6,56}=1.6, \mathrm{P}>\right.$ 0.05 , ANOVA, respectively; Figure $1 \mathrm{~A}$ and $\mathrm{B}$ ).

Figure 3 shows the sites of drug microinjection in the CEA.

\section{Discussion}

Various studies have demonstrated that chemical or electric stimulation of different

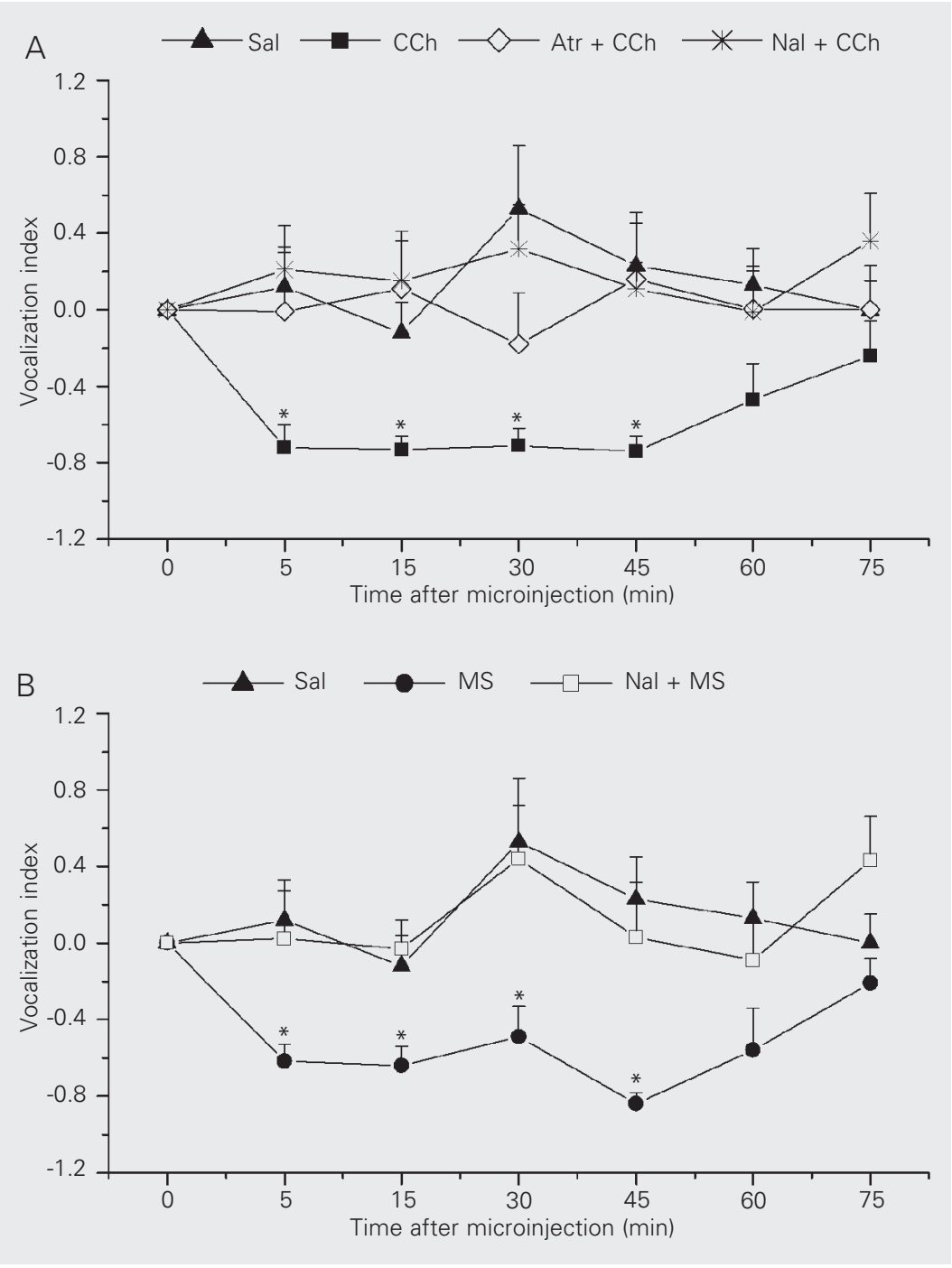

Figure 1. Cholinergic-opioidergic interaction in the central amygdala induces antinociception in the guinea pig. Data are reported as means \pm SEM of the vocalization index (VI) under control conditions (time zero, before microinjection) and after the administration of different drugs into the central nucleus of the amygdala (CEA) obtained for different experimental groups of conscious guinea pigs submitted to a peripheral noxious stimulus. The number of animals in each group was 7 to 11. A, VI after microinjection of saline (Sal, $0.9 \%, 0.2 \mu \mathrm{l}$; triangles); after carbachol microinjection (CCh, $2.7 \mathrm{nmol} / 0.2 \mu \mathrm{l}$; squares); after atropine (Atr, $0.7 \mathrm{nmol} / 0.2 \mu \mathrm{l}$ ) microinjection followed by CCh into the CEA (lozenges); after naloxone ( $\mathrm{Nal}, 1.3 \mathrm{nmol} / 0.2 \mu \mathrm{l})$ microinjection followed by $\mathrm{CCh}$ into the CEA (sextile). $B, \mathrm{VI}$ after microinjection of Sal (0.9\%, $0.2 \mu \mathrm{l}$; triangles); after morphine sulfate (MS; $2.2 \mathrm{nmol} /$ $0.2 \mu \mathrm{l}$; circles) and after Nal followed by MS (squares). ${ }^{*} \mathrm{P}<0.05$ compared to respective control (time zero) and to the Sal, Atr + CCh, Nal + CCh, and Nal + MS groups at each time of the experiment (Duncan test). 


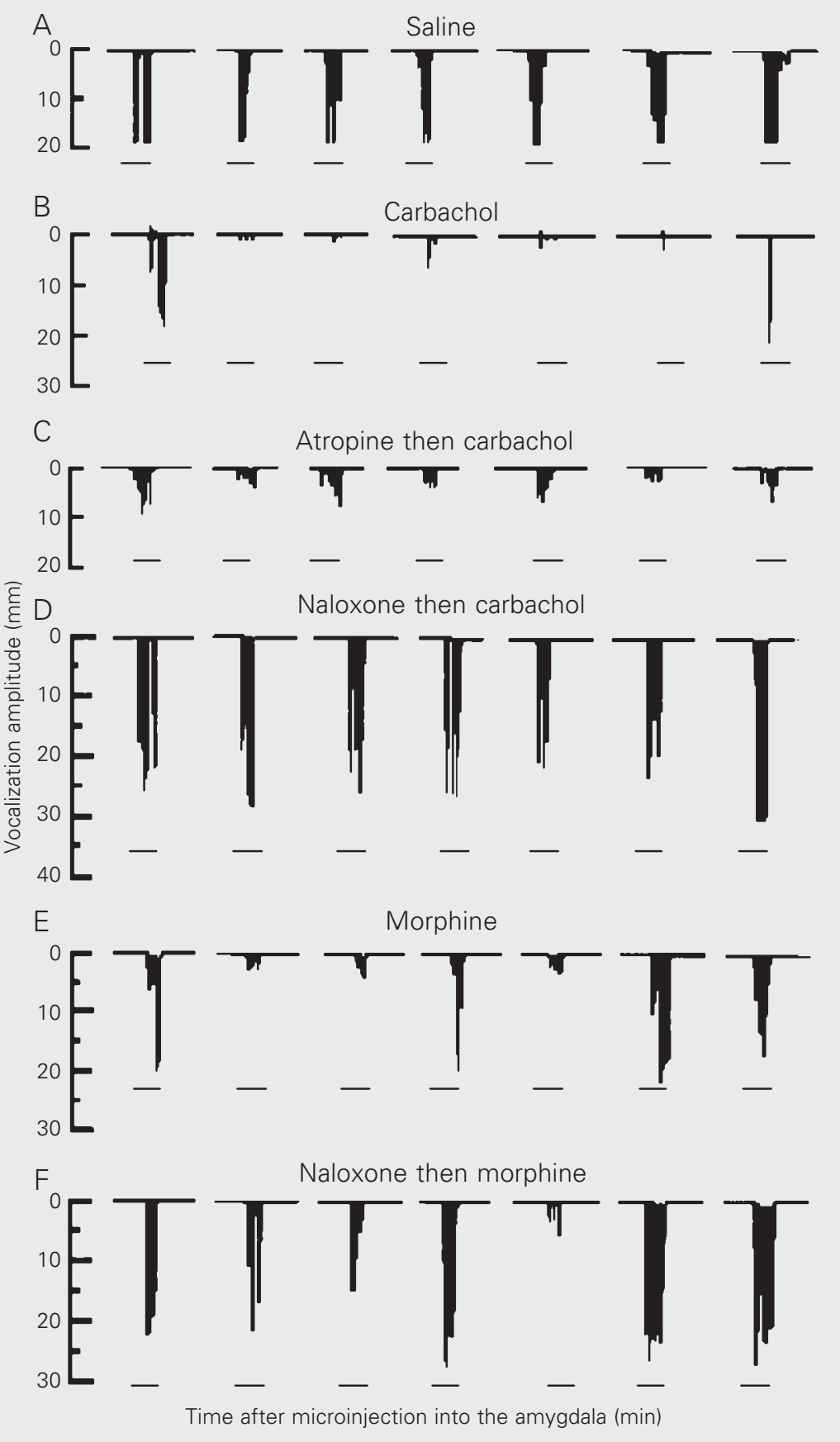

Figure 2. Schematic drawing of the vocalization amplitude $(\mathrm{mm})$ after administration of different drugs into the central nucleus of the amygdala (CEA) of guinea pigs. $A$, Animal microinjected with saline; $B$, animal treated with carbachol (CCh) into the CEA; $C$, animal treated with atropine (Atr) followed by CCh; $D$, animal microinjected with naloxone (Nal) followed by CCh; $E$, animal microinjected with morphine sulfate (MS); $F$, animal treated with $\mathrm{Nal}$ followed by MS into the CEA. The horizontal bar indicates the application of the noxious stimuli (3 s) at the different time intervals ( $\mathrm{min}$ ). The zero represents the vocalization amplitude during the control period (without saline or drug administration). The quantities of the drugs employed are given in the legend to Figure 1. brain sites is able to promote antinociception, with the PAG, dorsal raphe nucleus and magnus raphe nucleus having been extensively explored (21). On the other hand, some reports have shown the role of the amygdala in antinociception as well as its involvement in emotional modulation (2) and defensive responses (4). Probably, the amygdaloid circuitry that contributes to antinociception involves a connection with the neural substrate that is activated in defensive antinociception following fear behaviors $(3,12)$. On this basis, it is possible that the same neural substrate will be responsible for the modulation of defensive behavior and antinociception. In this respect, several studies have reported the involvement of some brain structures including the parabrachial area $(22,23)$, PAG $(24,25)$, lateral hypothalamus $(26,27)$, and amygdala $(4,6,14)$ in the modulation of defensive behavior and antinociception.

The involvement of the amygdaloid complex in nociceptive regulation has been demonstrated in different investigations $(3,6,12$, $13)$, but guinea pigs and the vocalization test are not commonly used in experiments destined to the study of the neural mechanisms of analgesia. In this respect, Oliveira and Prado (3) demonstrated that microinjection of carbachol into different amygdaloid nuclei (basolateral, lateral posterior and central) induced an increase of the withdrawal reflex in the tail-flick test in rats. Furthermore, the same treatment promoted behavioral alterations such as motor hyperactivity and masticatory movements. The authors suggested that the antinociception and behavioral alterations induced by the intraamygdaloid administration of carbachol depend on the activation of muscarinic receptors, because pretreatment with atropine prevented the behavioral and antinociceptive effect of carbachol. In addition, ip administration of diazepam blocked only the behavioral responses induced by carbachol administered into the CEA, indicating that the 
antinociceptive and behavioral responses induced by carbachol stimulation depend on different circuitries in the amygdala (3). These findings support the present results obtained for guinea pigs, which showed that carbachol stimulation of the CEA promoted antinociception evidenced by a decrease in the VI (Figure 1A), and also agree with the results of our previous study (16) in which carbachol promoted a decrease in the defensive response of tonic immobility. Taken together, these results suggest that the activation of the cholinergic system of the central amygdala is involved in the modulation of defensive behavior and antinociception.

Also, the results reported by Oliveira and Prado (28) showing that electric stimulation of the CEA promoted antinociception in the tail-flick test in rats and that this effect was blocked by the systemic administration of atropine, naloxone and propranolol indicate the participation of the cholinergic, opioidergic and adrenergic systems in the antinociception induced by CEA stimulation. In this context, in addition to the involvement of the cholinergic system of the CEA in nociceptive regulation, other neurotransmitters of this substrate are strongly involved in nociception. Manning (29) observed the lateralized loss of opioid antinociception (ip administration of morphine) after unilateral inactivation of the CEA in the formalin test. These results suggest a topographic ipsilateral organization in the descendent control of nociception. These data agree with those of the present study in which antinociception induced by the administration of carbachol or morphine sulfate into the CEA was observed in guinea pigs after application of a noxious electric stimulus to the thigh ipsilaterally to the microinjection site of the drug. Moreover, Pavlovic et al. (14), studying the opioidergic system of the amygdala, showed that the administration of morphine or $B$ endorphin into the CEA promoted antinociception in the tail-flick test and in the jump test in rats. These results agree with our

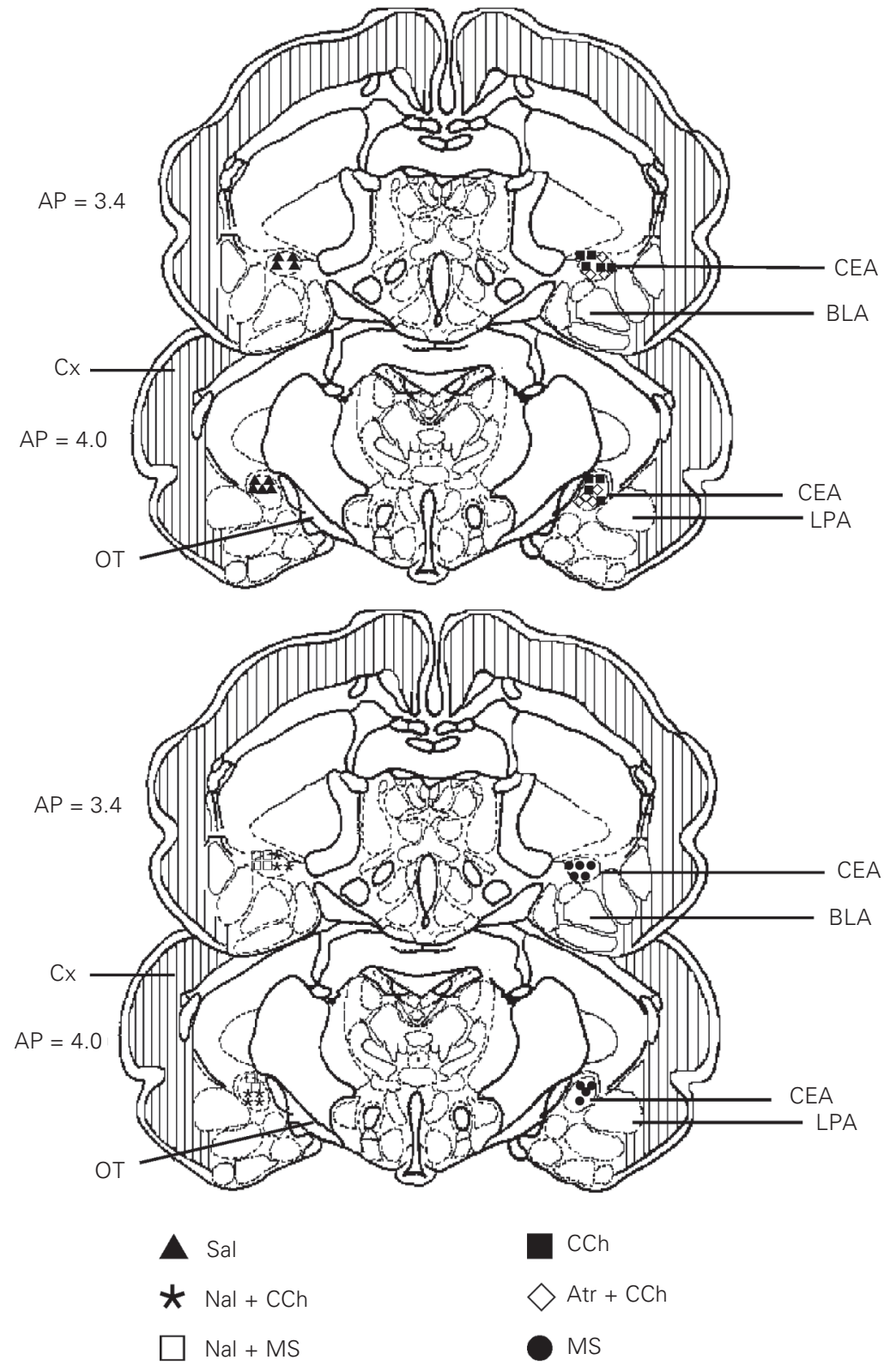

Figure 3. Schematic drawing of frontal sections obtained from representative levels of the guinea pig amygdala. The triangles represent the sites where saline (Sal) was microinjected; the filled squares indicate the sites where carbachol (CCh) was microinjected; the lozenges represent the sites where atropine (Atr) followed by CCh was microinjected; the asterisks indicate the sites where naloxone (Nal) followed by CCh was microinjected; the circles indicate the sites where morphine sulfate (MS) was microinjected, and the open squares represent the sites of microinjection of $\mathrm{Nal}$ followed by MS into the CEA. The number of points in the figure is less than the total number of animals $(N=53)$ because of several overlaps. All microinjections were made on the left side, but Sal, Nal + CCh and Nal + MS sites are illustrated on the right for clarity. BLA = basolateral nucleus of the amygdala; $\mathrm{CEA}=$ central nucleus of the amygdala; $\mathrm{CX}=$ cerebral cortex; $\mathrm{LPA}=$ lateral posterior nucleus of the amygdala; OT = optic tract. 
findings showing that morphine sulfate administration into the CEA induced antinociception in the vocalization test, as demonstrated by a decrease in VI (Figure 1B), and that this effect could be prevented by preadministration of naloxone into the same site, suggesting that the effect of morphine sulfate occurs at the level of local opioidergic receptors.

Our results again showed that the antinociception induced by carbachol or morphine sulfate administered into the CEA is prevented by pretreatment with naloxone at the same site, suggesting that a cholinergic-opioidergic interaction in this substrate is responsible for the nociceptive modulation. In this respect, Guimarães et al. (24) reported that antinociception induced by carbachol administration into the dorsal PAG of rats evaluated by the vocalization test was blocked by treatment with atropine, mecamylamine or naloxone at the same site. These results demonstrated the interaction of the cholinergic and opioidergic systems in dorsal PAG modulation of antinociception. The same interaction was also observed in our previous report (19) but in the ventral PAG when carbachol or morphine sulfate stimulation promoted a decrease of VI in guinea pigs. Again, a similar cholinergic-opioidergic interaction was demonstrated in the CEA, but involved in the control of the defensive behavior of tonic immobility (16). On this basis, we propose that cholinergic transmission might activate the release of endorphins/enkephalins from interneurons of the CEA, resulting in a decreased VI. Finally, in agreement with Harris (30), it is possible that the CEA participates in descending antinociceptive mechanisms through its anatomical-functional connection with the PAG. In this respect, Harris (30) suggested that defensive systems in the amygdala are able to activate PAG antinociceptive mechanisms via direct, possibly enkephalinergic, projections that inhibit the local GABAergic neurons in the PAG. In addition, the descending projections from the PAG to intraspinal antinociceptive mechanisms are under the tonic inhibitory influence of local GABAergic neurons.

The results of the present study showed that the activation of the cholinergic or opioidergic system of the CEA promotes antinociception in guinea pigs as evidenced by a decrease of the vocalization index. In addition, antinociception produced by cholinergic stimulation of the CEA depends on opioid synapses present at the same site.

\section{Acknowledgments}

We thank Mr. Rubens Fernando de Melo for histological processing of the specimens.

\section{References}

1. Kapp BS, Whalen PJ, Supple WF \& Pascoue JP (1992). Amygdaloid contributions to conditioned arousal and mental and sensory information processing. In: Aggleton JP (Editor), The Amygdala: Neurobiological Aspects of Emotions, Memory and Mental Dysfunction. Wiley-Liss, New York.

2. Gallangher M \& Chiba AA (1996). The amygdala and emotion. Current Opinion in Neurobiology, 6: 221-227.

3. Oliveira MA \& Prado WA (1994). Antinociception and behavioral manifestations induced by intracerebroventricular or intra-amygdaloid administration of cholinergic agonists in the rat. Pain, 57: 383391.

4. Leite-Panissi CRA, Monassi CR \& Menescal-de-Oliveira L (1999).
Role of amygdaloid nuclei in the modulation of tonic immobility in guinea pigs. Physiology and Behavior, 67: 717-724

5. Danielson EH, Magnunson DJ \& Gray TS (1989). The central amygdaloid nucleus innervation of the dorsal vagal complex in rat: a Phaseolus vulgaris, leukoagglutinin lectin anterograde tracing study. Brain Research Bulletin, 22: 705-715.

6. Oliveira MA \& Prado WA (2001). Role of PAG in the antinociception evoked from the medial or central amygdala in rats. Brain Research Bulletin, 54: 55-63.

7. Fox RJ \& Sorenson CA (1994). Bilateral lesions of the amygdala attenuate analgesia induced by diverse environmental challenges. Brain Research, 648: 215-221. 
8. Ahn DK, Kim YS \& Park JS (1999). Central-amygdaloid carbachol suppressed nociceptive jaw opening reflex in freely moving rats. Progress in Neuro-Psychopharmacology and Biological Psychiatry, 23: 685-695.

9. Bernard JF \& Besson JM (1990). The spino(trigemio)pontoamygdaloid pathway: electrophysiological evidence for an involvement in pain processes. Journal of Neurophysiology, 63: 473-490.

10. Chow TW \& Cummings JL (2000). The amygdala and Alzheimer's disease. In: Aggleton JP (Editor), The Amygdala: A Functional Analysis. Oxford University Press, New York.

11. Cassel MD, Gray TS \& Kiss JZ (1986). Neuronal architecture in the rat central nucleus of the amygdala: a cytological, hodological and immunocytochemical study. Journal of Comparative Neurology, 246: 278-299.

12. Manning $\mathrm{BH} \&$ Mayer DJ (1995). The central nucleus of the amygdala contributes to the production of morphine antinociception in the formalin test. Pain, 63: 141-152.

13. Helmstetter FJ, Bellgowan PSF \& Poore LH (1995). Microinfusion of mu but not delta or kappa opioid agonist into the basolateral amygdala results in inhibition of the tail-flick reflex in pentobarbital-anesthetized rats. Journal of Pharmacology and Experimental Therapeutics, 275: 381-388.

14. Pavlovic ZW, Cooper ML \& Bodnar RJ (1996). Opioid antagonists in the periaqueductal gray inhibit morphine and ß-endorphin analgesia elicited from the amygdala of rats. Brain Research, 741: 13-26.

15. Leite-Panissi CRA, Coimbra NC \& Menescal-de-Oliveira L (2003). The cholinergic stimulation of the central amygdala modifying the tonic immobility response and antinociception in guinea pigs depends on the ventrolateral periaqueductal gray. Brain Research Bulletin, 60: 167-178.

16. Leite-Panissi CRA \& Menescal-de-Oliveira $L$ (2002). Central nucleus of the amygdala and tonic immobility in guinea pigs. Brain Research Bulletin, 58: 13-19.

17. Zimmermann M (1983). Ethical guidelines for investigations of experimental pain in conscious animals. Pain, 16: 109-110.

18. Menescal-de-Oliveira L \& Lico MC (1977). Pain modulation in the adrenergically stimulated area postrema in the guinea pig. Physiology and Behavior, 19: 359-364.
19. Menescal-de-Oliveira L, Brentegani MR, Leite-Panissi CRA \& Monassi CR (1999). Cholinergic-opioidergic interaction in the ventrolateral periaqueductal gray matter inducing antinociception in guinea pigs. 9th World Congress on Pain, August 22-29, 1999 , Vienna, Austria, 148 (Abstract 58).

20. Rössner W (1965). Stereotaktischer Hirnatlas vom Meerschweinchen. Palla Verlag, Munich, Germany.

21. Besson JM \& Chaouch A (1987). Peripheral and spinal mechanisms of nociception. Physiological Reviews, 67: 167-186.

22. Katayama Y, Watkins LR, Becker DP \& Hayes RL (1984). Non-opiate analgesia induced by carbachol microinjection into the pontine parabrachial region of the cat. Brain Research, 296: 269-283.

23. Menescal-de-Oliveira L \& Hoffmann A (1993). The parabrachial region: a possible substrate shared by the systems that modulate pain and tonic immobility. Behavioural Brain Research, 56: 127-132.

24. Guimarães APC, Guimarães FS \& Prado WA (2000). Modulation of carbachol-induced antinociception from the rat periaqueductal gray. Brain Research Bulletin, 51: 471-478.

25. Monassi CR, Leite-Panissi CRA \& Menescal-de-Oliveira L (1999). Ventrolateral periaqueductal gray matter and the control of tonic immobility. Brain Research Bulletin, 50: 201-208.

26. Dafny N, Dong WQ, Prieto-Gomez C, Reyes-Vasquez C, Stanford J \& Qiao JT (1996). Lateral hypothalamus: site involved in pain modulation. Neuroscience, 70: 449-460.

27. Oliveira L, Hoffmann A \& Menescal-de-Oliveira L (1997). The lateral hypothalamus in the modulation of tonic immobility in guinea pigs. NeuroReport, 8: 3489-3493.

28. Oliveira MA \& Prado WA (1998). Antinociception induced by stimulating amygdaloid nuclei in rats: Changes produced by systemically administered antagonists. Brazilian Journal of Medical and Biological Research, 31: 681-690.

29. Manning BH (1998). A lateralized deficit in morphine antinociception after unilateral inactivation of the central amygdala. Journal of Neuroscience, 18: 9453-9470.

30. Harris JA (1995). Descending antinociceptive mechanisms in the brainstem: their role in the animal's defensive system. Journal of Physiology, 90: 15-25. 